\title{
Visual techniques in the practice of implementing various inclusive approaches to learning in the context of digitalization
}

\author{
Tatyana Byundyugova ${ }^{1 *}$, Oksana Kholina ${ }^{2}$, and Elena Petrova $^{2}$ \\ ${ }^{1}$ Southern University (IMBL), 344006 Rostov-on-Don, Russia \\ ${ }^{2}$ Taganrog Institute named after A. P. Chekhov (branch) of RSEU (RINH), 347900, Taganrog, Russia
}

\begin{abstract}
The article systematizes the main approaches and practical directions of implementation of inclusion in the educational environment (diagnostic, social, installation, resource, differentiated, dynamic, system, conductive, axiological approaches). Among the materials of the work there is a description of the key components of the implementation of inclusive theory and practice in the digital environment, an analysis of the key directions in working with students with special educational needs. The work contains the result of systematization of the use of inclusion in different approaches, taking into account all the subjects of the educational space in the context of different planes, including taking into account the possibilities of using visual technologies of work in the digital space. The article describes the results of the use of visual technologies (mind maps, scribing, crossence) in the digital environment in order to optimize the inclusive practices of the educational space, in particular, describes the results of native teaching of children without special educational needs and their parents to participate in inclusion, its support in mass schools. The use of visual technologies was effective - interest in the problem increased, and parents and children were actively involved in the discussion. All this allowed us to conclude that working in a digital environment using visual technologies is a simple and mass way to involve people in the problems of implementing inclusive practices.
\end{abstract}

\section{Introduction}

Modern legal, informational, socio-economic, and technological capabilities have created optimal conditions for the implementation of inclusive education, especially in the framework of the development of the digital space. They meet the requirements and modern practices of working with children with special educational needs as much as possible. A key form of implementing inclusive education in the digital environment is also associated with the possibilities of co-education within the framework of mass schools. It is such an environment that will allow us to remove information, socio-psychological barriers and significantly reduce all existing restrictions on the participation of this category of the population in social life and education. The development and implementation of projects of

*Corresponding author: tach_29@mail.ru 
a parallel inclusive educational environment in a mass school appears already in the middle of the 20th century and by the beginning of the 21 st century begins to gain momentum, having a sufficient basis. Research in this area has been quite diverse: from legal and economic aspects to taking into account the personal and mental characteristics of children in the learning process. All this has formed the basis for the development of a system of inclusive education in the digital environment at the present time [14].

Inclusive education in the digital environment is a form of organizing the educational process with the help of information technologies and technical means, which allows you to include children with special educational needs in a mass school [8].

Inclusion, according to some authors, should be differentiated from integration, since it (inclusion) initially considers all children, without any exceptions, as part of the general education system, taking into account the conditions of the modern digital environment. So the digital environment removes the need for a separate special adaptation for children with special educational needs, they are initially part of the digital educational space [2].

\section{Materials and methods results}

The key task of inclusive practice in the digital space is the readiness of any educational organization in the future to accept children with different learning opportunities. All this entails changes in the structure and work of educational organizations in the digital environment, but also changes in the views and professional outlook of teachers who are used to considering their work within the framework of teaching certain groups of children $[5]$.

The researchers identify the following key components of implementing inclusive theory and practice in the digital environment:

- systematic inclusion of children with special educational needs in a school that they could attend if they did not have a disability;

- the lack of "sorting" of children, the implementation of training in mix groups;

- children with special educational needs are taught in groups of children that correspond to their age norm and only;

- interaction exclusively taking into account each individual situation and constant coordination of resources and methods of education, development, training;

- efficiency in the digital environment as the main style and principle of the educational organization [15].

In modern conditions, four key directions were formed in working with students with special educational needs in a digital environment:

1. Expanded access to education, where the main goal is to expand educational opportunities for students with special educational needs, from ethnic minorities, from disadvantaged groups. Within the framework of this direction, the educational policy is implemented through various social and economic forms of interaction with sponsors and partners in the digital environment [13].

2. The organization of a digital space for the interaction of children with different educational needs, first in the framework of leisure and extracurricular activities.

3. The organization of a digital space for the interaction of children with different educational needs within several separate subjects or courses. Especially focus on those that are well received and assimilated by children with special educational needs. This is the stage of digital integration.

4. The organization of a digital space for the interaction of children with different educational needs in the framework of a full-fledged education program of a mass school in equal conditions with other students. This is the stage of digital inclusion. 
These directions can be implemented as part of the modernization of the educational organization: redevelopment of the space, development of a new program [3].

Currently, within the framework of developing areas of specialized education for students with special educational needs, the most promising and relevant is an inclusive direction that meets all the requirements of modern society and the humanization of education, implemented in a digital environment [12].

Within the framework of the research work, various approaches were systematized, which are presented in the theory and practice of implementing digital inclusion.

1. Diagnostic approach in the digital environment. Within the framework of this approach, an inclusive direction in the work of educational organizations begins to form as part of the development of a general work strategy and the creation of methodological materials and educational programs. The main task is to diagnose and monitor the implementation of inclusive programs in the digital environment. Here you can use expert surveys, feedback questionnaires, which will allow you to adjust the process of training and education. The diagnostic approach allows you to diagnose and track the motives and interests of students in the current mode, adjust plans and individual learning routes in the digital environment in accordance with them [6].

2. Social approach in the digital environment. Within the framework of this approach, more attention is focused on the process of adapting the educational environment and society to the capabilities of a student with special educational needs, creating a system of necessary facilitating social connections in the digital environment and developing the abilities of such a student, taking into account their demand where he lives, studies or works. This approach implies the fullest possible involvement of students with special health conditions in the life of society, so the training program should include training in certain social skills that will allow the student to become independent and learn how to interact with people [10].

3. The installation approach in the digital environment. T. Booth notes that the effectiveness of the inclusion of children who have special educational needs in the school and the digital environment should be based on changing the socio-psychological and behavioral attitudes of all subjects of the education system: teachers, students, parents, administration. Inclusion is a transformation that must undergo a long preparation aimed at developing an understanding of the diversity of students that the educational system has to work with. The attitude should be formed to perceive such diversity not as a source of difficulties, but as an ordinary reality that must be accepted, to understand the norm not as something homogeneous and stable, but in its diversity [8].

4. The resource approach in the digital environment focuses primarily on the competent equipment of the educational organization, where the space and teaching staff allow students with special educational needs to fully and naturally join the group of peers. A resource within this approach is an additional provision for students with special educational needs (additional chaperone, additional space, assistance, materials, special equipment). Such resources for effective learning can be for children with a specific type of impairment or with several. Teachers can also participate in supporting students with special educational needs in other mass schools. Assistants or tutors may also be involved as part of additional assistance [5].

5. A differentiated approach in the digital environment is based on the division of the educational process by educational programs, learning goals, teaching methods, and the assessment of achievements. To solve specific educational tasks, an individual training program is used, which is divided according to the degree of complexity, taking into account the specifics of violations. This approach also implies periodic individual work, which requires modification of resources, flexibility of pedagogical styles, methods, strategies, and the educational environment. To implement differentiation, which is 
primarily focused on the student, it is important for teachers to clearly present the current level of knowledge, skills, abilities, and the overall level of mental development. It is necessary to have an idea of the personal characteristics and motivation of the student [1].

6. Dynamic approach in the digital environment. This approach is based on the principle of "dynamic integration" - an approach that assumes that students with special educational needs do not have to be in the same educational space with other students all the time. It is enough for them to be in a certain place and at a certain time to participate in specific activities. The dynamic approach significantly increases the level of teachers ' skills, which has a positive impact on the achievements of all students. Also, in general, it allows you to reduce the level of stress of the subjects of the educational process, increase empathy and more actively involve parents in educational activities. This approach is most competently implemented at the very beginning of the introduction of inclusive practice in mass schools [2].

7. A systematic approach in the digital environment allows you to implement inclusion as efficiently and quickly as possible. But this approach requires the most involvement and resources, since the well-being of students with special educational needs depends on a large number of different factors: socio-cultural, pedagogical, psychological, economic, and legal [11]. This approach is related to the general ecological concept of the development of society. Within the framework of this approach, it is important to organize cooperation with digital platforms, educational portals, where children with special educational needs can fully interact and socialize in a group, organization, society. All this will allow us to reach a new level of development. This approach takes into account the complex system of interaction between different structures and groups. It can be tracked and constructed in a digital environment [9].

8. The conductive approach to the implementation of inclusive practice in the digital environment accumulates the efforts of the subjects of the educational process, who directly implement it in different organizations in attempts to organize assistance and cooperation with those who are not directly involved in the implementation of inclusive education parents, classmates. This approach, thanks to digital technologies, allows you to implement inclusive practices in the horizontal and vertical direction. Systematic efforts in the "360degree" format (when classmates, family, teachers, administration, psychologists, and thirdparty organizations are included) will have the expected effect. It also increases the effectiveness of communication with an unfamiliar environment, reduces the subjective assessment of personal characteristics [7].

9. The axiological approach in the digital environment implies that, along with various means, methods and technologies, values are an important part of a complex system of "inclusive education". This approach is related to the ideological foundations of inclusive theory and practice. The values of the practice of inclusion are clearly formulated in the following basic provisions: a person is valuable in himself, regardless of his achievements, results; all people have the right to communicate, interact, and be heard. Real education, conscious and systematic, based on humanistic values, can only be realized in the context of meaningful communication based on universal ideals. This approach involves going beyond the system of pedagogical knowledge [3].

\section{Results and discussion}

In general, all the described approaches contain one key idea - effective implementation of inclusion is possible only in the system version, when the subjects of the educational process are directly involved in the practice, but also those who are not directly responsible for inclusion, but give a facilitating effect. 
The easiest way to start actively and massively implement the practice of inclusion in the digital environment.

Digital inclusion is a way of teaching students with special educational needs in groups of children from a mass school using individual digital educational routes. This will optimize socialization, soft skills, and increase the level of empathy and social intelligence in children and adolescents with and without special educational needs.

As part of any approach, it is necessary to carry out preparatory work, for which it is most convenient to use visual technologies in the digital environment.

Visualization allows, on the one hand, to actively work with cognitive constructs that are components of the inner world of the student's personality, on the other hand, it is a technique that allows you to use the visual format of analyzing material, data, including those related to the implementation of inclusive practice.

A previous study showed that only $30 \%$ of students without special educational needs and $32 \%$ of parents are ready to be included in inclusive learning practices. Therefore, it is necessary to conduct training for them in a native format, which will increase awareness of the attitude to inclusion.

As part of this work, parents and children who are not directly involved in inclusive practices at school were trained. The training was conducted in a digital environment, on the Zoom platform, as part of parent meetings and classroom hours during the distance learning period using visual technologies (scribing, intelligent maps, crosscience). All training included informing children and parents about the possibilities of inclusion, about its benefits for them. In terms of visual tasks, they were asked to use their active imagination to create a "treasure map" of inclusion. The training did not include calls for participation, inclusion of consciousness, appeal to feelings of shame and guilt.

Table 1. Analysis of interest in involvement in inclusion in the educational process.

\begin{tabular}{|l|c|c|c|c|}
\hline & \multicolumn{2}{|c|}{$\begin{array}{l}\text { Before learning period } \\
\text { using visual technologies }\end{array}$} & \multicolumn{2}{|c|}{$\begin{array}{l}\text { After learning period } \\
\text { using visual technologies }\end{array}$} \\
\cline { 2 - 5 } & Children & Parents & Children & Parents \\
\hline $\begin{array}{l}\text { Desire to learn more about } \\
\text { inclusion }\end{array}$ & $23[\%]$ & $15[\%]$ & $49[\%]$ & $59[\%]$ \\
\hline $\begin{array}{l}\text { General awareness of } \\
\text { inclusion issues }\end{array}$ & $12[\%]$ & $20[\%]$ & $58[\%]$ & $69[\%]$ \\
\hline $\begin{array}{l}\text { Reducing anxiety about } \\
\text { engaging in an inclusive } \\
\text { environment }\end{array}$ & $34[\%]$ & $23[\%]$ & $46[\%]$ & $69[\%]$ \\
\hline
\end{tabular}

In $78 \%$ of cases among parents and in $59 \%$ of cases among children of primary school age $(77 \%$ - teenagers), there was an interest in inclusive practice, there was a lively discussion about what their children can learn if they help children with special educational needs.

\section{Conclusion}

Thus, as the research conducted in theory and practice shows, one of the most significant problems is the lack of readiness of mass school teachers for new forms of professional activity and for a new, more serious responsibility. Such a picture is typical for most countries that have turned to the implementation of inclusive practices in education. The program of normalization and inclusion cannot be implemented "in one day", by simply "placing" students who have special educational needs, within a simple set of administrative decisions to transfer a special school to a mass one. Western approaches note that this requires significant, preventive organizational and methodological work, which involves certain training of teachers and families, the search for optimal ways to modify 
educational programs, the development of new systematic and differentiated methodological approaches, methods, techniques that will allow everyone to participate in the learning process in accordance with their characteristics, capabilities and needs.

\section{References}

1. V.A. Ardzynba, Psychological Science and Education 5 http://www.psyedu.ru/ files/articles/2282/pdf_version. pdf, pp. 23-29, last accessed 2020/11/24 (2017).

2. R. Dyminstein, I. Larikova, Integration or inclusion? Disputes about words and unresolved problems in the education of special children. www.osoboedetstvo.ru/rights/idprav/files/integr_kratk 5_pravl.doc last accessed $2020 / 11 / 24$

3. L.K. Kurmysheva, Siberian Pedagogical Journal 9, 221-224 (2019)

4. D. Mitchell, Effective pedagogical technologies of special and inclusive education (Perspective, Moscow, 2019)

5. ed. by V. L. Ryskina, E. V. Samsonova, Russian and foreign studies in the field of inclusive education (Forum, Moscow, 2018).

6. T.Yu. Khotyleva, T.V. Akhutina, Psychological Science and Education 5, 1-12 (2019) http://psyjournals.ru/psyedu_ru/2010/n5/Hotyleva_Ahutina_full.shtml last accessed 2020/21/12.

7. D.L. Ferguson, G. Meyer, L. Jeanchild, L. Juniper and J. Zingo, Journal of the Association for Persons with Severe Handicaps 17, 218-226 (2018)

8. D.K. Lipsky, A. Gartner, Achieving full inclusion: Placing the student at the center of educational reform, W. Stainback and S. Stainback (Eds), Controversial issues confronting special education: Divergent perspectives (Allyn \& Bacon, Boston, 1991)

9. C.L. Salisbury, M.M, Palombaro, W.M. Hollowood, The Journal of the Association for Persons with Severe Handicaps 18, 75-84 (1993)

10. T. Tsyrlina-Spady, Education and self-development 2, 212-216 (2014)

11. Ch. Coleman-King, V. Adams-Bass, K. Bentley-Edwards, Soc. Sci 10(3), 99 (2021) doi.org/10.3390/socsci10030099

12. L. Espino-Díaz, J. Alvarez-Castillo, C. Hernandez-Lloret, Soc. Sci. 9(5), 72 (2020) doi.org/10.3390/socsci9050072

13. D. Juárez-Varón, V. Tur-Viñes, A. Rabasa-Dolado, Soc. Sci. 9(9), 162 (2020) doi.org/10.3390/socsci9090162

14. K. Rambaree, N. Nässén, Soc. Sci. 10(3), 95 (2021) doi.org/10.3390/socsci10030095

15. Ch. Tortorelli, P. Choate, M. Clayton, Soc. Sci. 10(1), 7 (2021) doi.org/10.3390/socsci10010007 